\title{
Correction to: Radiolabeled PLGA Nanoparticles for Effective Targeting of Bendamustine in Tumor Bearing Mice
}

Iliyas Khan ' Avinash Gothwal' - Ankur Kaul ${ }^{2}$. Rashi Mathur ${ }^{2} \cdot$ Anil Kumar Mishra $^{2}$. Umesh Gupta ' (1)

Published online: 11 October 2018

(C) Springer Science+Business Media, LLC, part of Springer Nature 2018

\section{Correction to: Pharm Res}

https://doi.org/ I 0.1 007/s I I 095-0 I 8-

2482-6

The typesetter did not use the Fig. 6 provided by the author with his proof corrections, and instead duplicated Fig. 7 by the Fig. 6 caption. The original article has been corrected.

The online version of the original article can be found at https://doi.org/l 0 . | 007/s | |095-0|8-2482-6

\footnotetext{
Umesh Gupta

umeshguptal75@gmail.com; umeshgupta@curaj.ac.in; http://

www.curaj.ac.in

Department of Pharmacy, School of Chemical Sciences and Pharmacy Central University of Rajasthan Bandarsindri, Ajmer, Rajasthan 305817, India

2 Division of Cyclotron and Radiopharmaceutical Sciences, Institute of Nuclear Medicine and Allied Sciences New Delhi I 10054, India
} 